\title{
Biological and genetic evaluation of IL-23/IL-17 pathway in ankylosing spondylitis patients
}

\author{
HULYA DEVECI I AYLA CAGLIYAN TURK ${ }^{2}$, ZELIHA CANSEL OZMEN ${ }^{3}$, AYSE KEVSER DEMIR \\ SAFIYE UMUT SAY COSKUN
}

${ }^{1}$ Department of Physical Medicine and Rehabilitation, Tokat Gaziosmanpaşa University School of Medicine, Turkey

${ }^{2}$ Department of Physical Medicine and Rehabilitation, Hitit University School of Medicine, Turkey

${ }^{3}$ Department of Biochemistry, Tokat Gaziosmanpaşa University School of Medicine, Turkey

${ }^{4}$ Department of Internal Medicine, Tokat Gaziosmanpaşa University School of Medicine, Turkey

${ }^{5}$ Department of Microbiology, Tokat Gaziosmanpaşa University School of Medicine, Turkey

\begin{abstract}
Ankylosing spondylitis is the most common form of the chronic inflammatory disease group known as spondyloarthritides. Recent discoveries of the CD4+ Th17 cells and IL-23/IL-17 axis have changed the paradigms in many autoimmune diseases. In this study, we aimed to evaluate the importance of IL-23/IL-17 pathway and IL-23 receptor polymorphism in the pathogenesis of ankylosing spondylitis. Blood samples for this study were obtained from 109 ankylosing spondylitis patients and 40 healthy control subjects. Serum levels of TNF- $\alpha, I L-6, I L-17$, and IL-23 were measured by the ELISA method. The IL-23R gene polymorphisms rs 11209026 (Arg381Gln) and rs4131362 (Val362Ile) were performed by the Sanger Sequence method. IL-6 levels were higher in the active and inactive ankylosing spondylitis groups than in the control group. However, levels of IL-17 and IL-23 were lower in the patient group. The frequency of IL-23R gene rs 11209026 and rs 4131362 polymorphism were $3.7 \%$ and $8.3 \%$ in the patient, respectively. As a result, dysregulation of the IL-23 / IL-17 pathway, which is caused by reduced levels of IL-17 and IL-23 in systemic circulation in patients with ankylosing spondylitis, may contribute to the pathogenesis of the disease by systemically producing chronic autoimmune inflammation.
\end{abstract}

Key words: polymorphism, ankylosing spondylitis, cytokine, IL-17, IL-23, signalling pathways.

(Centr Eur Immunol 2019; 44 (4): 433-439)

\section{Introduction}

Ankylosing spondylitis (AS) is a major subtype of the chronic inflammatory disease group known as spondyloarthritides. The pathogenesis and aetiology of AS are not precisely understood. Complex interactions of environmental factors and immune responses are thought to play a role in the development of the disease [1]. It has long been known that the pathogenesis of AS has strong genetic components, and that genetic factors influence immune responses and AS progression [2,3]. The most important evidence of the genetic component of AS is the presence of the strong association between the pathogenesis of the disease and the HLA-B27 antigen. However, the contribution of HLA-B27 to AS genetic risk is only $16 \%$. For this reason, it is thought that some different genetic factors other than HLA-B27 are involved in the pathogenesis of the disease. Although the pathogenesis of AS is not fully understood, it has been suggested that increasing blood levels of certain pro-inflammatory cytokines (IL-1 $\beta$,
IFN- $\gamma$ TNF- $\alpha$, IL-6, IL-17, and IL-23) may play a role in the pathogenesis of AS [4, 5].

The recent discovery of CD4+ Th17 T cells and interleukin (IL)-23/IL-17 axis altered the paradigms and the role of Th1 cells in many autoimmune diseases [6]. Th17 cells, which are the third subtype of CD4+ T effector cells, are characterised by the production of proinflammatory cytokines; mainly IL-21, IL-22, TNF-a, and IL-17. Apart from host defence, IL-17 has been proven to be critical in the pathogenesis of various autoimmune diseases such as RA, SLE, SS, psoriasis, and inflammatory bowel disease [7-10]. IL-23 is a member of the IL-12 family. The bioactive forms of IL-12 consist of the p35/p40 heterodimer, whereas IL-23 consists of p40 and p19 subunits. IL-23 is not only synergistic with IL-6 and IL- 1 to stimulate Th17 development, but also it stimulates Th17 development and prolongs IL-17 production [11]. The relationship between AS disease activity, function, and spinal mobility and IL-17 and IL-23 are not fully understood [12-15]. Polymorphisms in the IL-23R chain may influ- 
ence IL-23 responses. The frequency of a functional single nucleotide polymorphism (SNP) in the IL-23 receptor gene (IL-23R; rs11209026, 1142 G wild-type A reduced function, Arg381Gln, R381Q) is significantly higher among healthy controls than in patients, suggesting a protective effect of the rare allele from immune-mediated chronic inflammation. The SNP rs11209026 encodes an amino acid change (Arg381Gln) in the protein product and has functional consequences; thus, R381Q is a causal variant [16]. To assess the contribution of IL-23R SNPs to susceptibility to AS, we targeted two nonsynonymous SNPs: rs11209026 (c.1142G>A, p.Arg381Gln) and rs41313262 (c.1084 G>A p.Val362Ile). This study was the first to evaluate the variant of IL-23R rs41313262 in AS patients. The aim of this study is to evaluate the role of IL-23/IL-17 pathway and IL-23R polymorphism in the pathogenesis.

\section{Material and methods}

In this study, blood samples were collected from 109 AS patients ( 80 males and 29 females, mean age 40.3 \pm 12.1 years) who were diagnosed with AS according to the modified New York criteria [17]. Control blood samples were obtained from 40 healthy subjects (25 males and 15 females, mean age $42.2 \pm 10.4$ years) without any medical illness. To select the appropriate individuals in the study and to exclude inappropriate individuals, detailed health information and medical histories of patients were recorded. Exclusion criteria were determined as having chronic systemic or rheumatic diseases other than AS, the presence of infections or malignant tumours at that time, and use of steroids, cytotoxic drugs, and immunosuppressive agents during the preceding months. The study protocol was approved by our institutional ethical committee, and it conforms to the provisions of the Declaration of Helsinki. The aim of the study was described in detail to all subjects, and written, informed consent was obtained.

The disease activity was assessed by the Turkish version of the Bath Ankylosing Spondylitis Disease Activity Index (BASDAI) 29, and the functional status was measured by Turkish version of Bath Ankylosing Spondylitis Functional Index (BASFI) [18, 19]. BASDAI and BASFI are self-performed questionnaires in which high scores show higher activity of the disease and more severe deterioration. The clinical status was evaluated by Bath Ankylosing Spondylitis Metrology Index (BASMI). High scores indicate disease involvement in more skeletal regions [20]. The severity of pain was measured by a Visual Analogue Scale of 0-10 cm. All patients had sacroiliac joint radiographs, and sacroiliitis was confirmed by a qualified radiologist. AS patients were divided into two subgroups according to BASDAI scores. Patients with BASDAI score $\geq 4$ were accepted as "active patients" while others were accepted as "inactive patients" [21]. AS patients were divided into two subgroups according to the presence or absence of extraarticular involvement. Extraarticular involvement was considered as presence of uveitis, intestinal disease, heart, lung, skin, bone, and kidney involvement.

Serum IL-23, IL-17A, IL-6, and TNF- $\alpha$ levels were measured by using enzyme-linked immunosorbent assay (ELISA) in AS patients and in the healthy control group. Disease activity was assessed by laboratory parameters including ESR and CRP. C-reactive protein (CRP) and erythrocyte sedimentation rate (ESR) was measured and evaluated as inflammatory markers of AS. Serum CRP levels were measured by the immunoturbidimetric method (Roche, Mannheim, Germany) according to the manufacturer's instructions and the results expressed in $\mathrm{mg} / \mathrm{l}$. ESR was measured by the Westergren method, and the results were expressed in $\mathrm{mm} / \mathrm{h}$. Routine biochemistry and haemogram parameters were evaluated using a Roche Hytachi C501 analyser (Roche, Mannheim, Germany) and a Cell/ Dyn Ruby analyser (Abbott, Illinois, USA).

\section{Genotyping}

Venous blood was collected in EDTA tubes from patients with AS and from healthy controls. Genomic DNA was isolated in venous whole blood using the Exgene Clinic SV kit (GeneAll Biotechnology, Korea) according to the manufacturer's instructions. The integrity of the isolated DNA samples was checked by agarose gel electrophoresis. DNA samples were amplified by polymerase chain reaction (PCR) using forward (5 'CTTTCATTAACAGAGGAG 3') and reverse (5 'TAAGCCTCATTTAAGTCACC 3') primers designed specifically for rs11209026 and rs4131362 SNPs in the IL-23R gene (Sentegen Biotech). The PCR reaction was as follows, and the products were stored at $4{ }^{\circ} \mathrm{C}$ until the next procedure. The stability of the obtained PCR product was checked by agarose gel electrophoresis. PCR products were purified using the ExoSAP-IT PCR Cleanup kit (Affymetrix, USA). Sequencing of purified PCR products was performed using BigDye Terminator v1.1. Purification of the sequencing products was performed according to the manufacturer's instructions using the Expin Cleanup kit (GeneAll Biotechnology, Korea). DNA sequencing was performed by the Sanger method using a Hitachi 3130xl genetic analyser (Applied Biosystems, USA) with a POP7TM polymer. Chromatograms were visualised with sequencing analysis software v5.3.1 and evaluated using SeqScape software v2.6.0.

The genotype distributions and allele frequencies of the rs11209026 (c.1142G> A, p.Arg381Gln) and rs41313262 (c.1084 G>A. p.Val362Ile) polymorphisms of the IL-23R gene were compared between patients and healthy controls. Patients were divided into three groups as AA, AG, or GG genotypes according to $1142 \mathrm{G}>\mathrm{A}$ and 1084 G>A IL-23R gene genotypes.

HLA-B27 genotyping was performed on a Fluorion Detection System (Iontek) using the Real-Time PCR meth- 
od according to the manufacturer's instructions using an HLA B27 QLP 1.0 (Iontek) commercial kit.

\section{Statistical analysis}

All statistical analyses were performed with Statistical Package for Social Sciences (SPSS) 15.0 Package (SPSS Inc., Chicago, IL, USA). Descriptive statistics were presented as a mean \pm standard deviation. Results that do not show normal distribution are expressed as median (range) values. The Kolmogorov-Smirnov test was used for normality tests. The mean difference between the groups was assessed by Student's t-test and Mann-Whitney $U$ test. $\chi^{2}$ and logistic regression were used for the analysis of categorical data. Relationships between variables were tested using Pearson and Spearman correlation analysis. ROC curve graphs were used to compare sensitivity and specificity. $P$ values less than 0.05 were considered significant.

\section{Results}

Demographic and clinical characteristics of patients with AS and control groups are shown in Table 1. The CRP and ESR values of active and inactive AS patients were higher than values in the control group $(p<0.001)$. In addition, BASDAI and BASFI values of active AS patients were higher than inactive AS patients, as expected $(p<0.001)$. No significant difference was found between the other parameters.
When we compare the study parameters between AS patient groups and the control group, there was no significant difference $(p>0.05)$ between serum TNF- $\alpha$ levels of patients $(10.1 \pm 3.0 \mathrm{pg} / \mathrm{ml})$ and serum TNF- $\alpha$ levels of healthy controls $(p>0.05)$. Serum IL-6 levels $(55.7 \pm 29.5 \mathrm{pg} / \mathrm{ml})$ in AS patients were significantly higher than serum IL-6 levels $(37.9 \pm 14.2 \mathrm{pg} / \mathrm{ml})$ in healthy controls. On the other hand, serum IL-17 levels (405.8 $\pm 192.5 \mathrm{ng} / \mathrm{l})$ and IL-23 levels $(365.7 \pm 242.9 \mathrm{ng} / \mathrm{l})$ of AS patients were found to be significantly lower than serum levels in healthy controls (respectively, $574.0 \pm 197.8 \mathrm{ng} / 1$ and $502.0 \pm 228.4 \mathrm{ng} / \mathrm{l})(p<0.001)$.

When we compare the study parameters of active AS, inactive AS patient groups and control group; IL-6 levels of active and inactive AS patients were significantly higher than healthy controls, but no significant difference was found between active AS and inactive AS patient groups. IL-17 and IL-23 levels were significantly lower in both AS groups than in the control group, but no significant difference was found between the two patient groups (Table 1).

When the correlation between the study parameters and the clinical and laboratory results was analysed in the patient group, there was a positive correlation between TNF- $\alpha$ and IL- 6 values and CRP and ESR values, and a weak positive correlation between IL17 and IL-23 values and ESR values. Clinical parameter scales showed only a weak negative correlation between BASDAI values and IL-17 values. Among the study parameters, there

Table 1. Demographic and disease characteristics of the ankylosing spondylitis patients and healthy controls

\begin{tabular}{lcccc}
\hline Characteristics & Active AS $(\boldsymbol{n}=\mathbf{4 3})$ & Inactive AS $(\boldsymbol{n}=\mathbf{6 6})$ & Healthy control $(\boldsymbol{n}=\mathbf{4 0})$ & $\boldsymbol{p}$-value \\
\hline Age, years & $39.5 \pm 11.6$ & $40.7 \pm 12.5$ & $42.2 \pm 10.4$ & $>0.05$ \\
\hline Male/female & $31 / 12$ & $49 / 17$ & $25 / 15$ & $>0.05$ \\
\hline HLA-B27 (+) & $23(53.4 \%)$ & $40(60.6)$ & - & $>0.05$ \\
\hline Disease duration, years & $10.3 \pm 8.8$ & $10.9 \pm 11.9$ & $>0.05$ \\
\hline C-reactive protein, mg/l & $14.4 \pm 18.6$ & $13.0 \pm 18.1$ & $1.9 \pm 1.8$ & 0.001 \\
\hline Erythrocyte sedimentation rate, $\mathrm{mm} / \mathrm{h}$ & $21.9 \pm 17.5$ & $24.8 \pm 20.7$ & $0.0 \pm 3.7$ & $<0.001$ \\
\hline BASDAI & $5.5 \pm 1.3$ & $1.9 \pm 1.1$ & - & $<0.001$ \\
\hline BASFI & $5.4 \pm 2.5$ & $0.5 \pm 1.3$ & - & $>0.05$ \\
\hline BASMI & $2.8 \pm 2.1$ & $2.8 \pm 2.0$ & - & $>0.05$ \\
\hline Extra-articular involvement & $16(27.9 \%)$ & $16(24.6 \%)$ & $10.4 \pm 2.0$ & 0.454 \\
\hline TNF- $\alpha$, pg/ml & $9.7 \pm 2.5$ & $10.3 \pm 3.2$ & $10.5(6.4-17.2)$ & $<0.0001$ \\
\hline IL-6, pg/ml & $9.6(4.7-15.2)$ & $9.6(5.4-21.5)$ & $37.9 \pm 14.0$ & $<3.8(24.8-97.0)$ \\
\hline IL-17, ng/l & $62.3 \pm 38.1$ & $51.7 \pm 22.3$ & $574.0 \pm 197.8$ & $<0.0001$ \\
\hline IL-23, ng/l & $47.5(22.5-210.0)^{* *}$ & $47.3(18.4-139.2)^{* *}$ & $502.0 \pm 228.4$ & 0.004
\end{tabular}

Values are shown as mean $(S D) .{ }^{*}$ Significantly different from healthy control at $p<0.05{ }^{*}$ Significantly different from healthy control at $p<0.001$. BASDAIThe Bath Ankylosing Spondylitis Disease Activity Index, BASFI - The Bath Ankylosing Spondylitis Functional Index, BASMI - The Bath Ankylosing Spondylitis Metrology Index 
Table 2. Correlation analysis between the study parameters and the clinic parameters in patients with AS

\begin{tabular}{|c|c|c|c|c|c|c|c|c|}
\hline & \multicolumn{2}{|c|}{ TNF- $\alpha$} & \multicolumn{2}{|c|}{ IL-6 } & \multicolumn{2}{|c|}{ IL-17 } & \multicolumn{2}{|c|}{ IL-23 } \\
\hline & $\begin{array}{c}\text { Correlation } \\
\text { coefficient }\end{array}$ & $p$-value & $\begin{array}{c}\text { Correlation } \\
\text { coefficient }\end{array}$ & $p$-value & $\begin{array}{c}\text { Correlation } \\
\text { coefficient }\end{array}$ & $p$-value & $\begin{array}{l}\text { Correlation } \\
\text { coefficient }\end{array}$ & $p$-value \\
\hline TNF- $\alpha$ & - & - & 0.055 & 0.573 & -0.011 & 0.910 & -0.003 & 0.975 \\
\hline IL-6 & - & - & - & - & -0.029 & 0.770 & 0.049 & 0.613 \\
\hline IL-17 & - & - & - & - & - & - & $0.933^{* *}$ & $<0.0001$ \\
\hline CRP & $0.169^{*}$ & 0.043 & $0.389^{* * *}$ & $<0.001$ & 0.134 & 0.109 & 0.163 & 0.051 \\
\hline ESR & $0.255^{*}$ & 0.009 & $0.284^{*}$ & 0.003 & $0.226^{*}$ & 0.021 & $0.247^{*}$ & 0.011 \\
\hline BASDAI & -0.071 & 0.471 & 0.136 & 0.167 & $-0.204^{*}$ & 0.037 & -0.180 & 0.066 \\
\hline BASFI & 0.312 & 0.082 & 0.183 & 0.316 & -0.298 & 0.097 & -0.231 & 0.203 \\
\hline BASMI & 0.117 & 0.238 & 0.140 & 0.156 & 0.090 & 0.361 & 0.126 & 0.204 \\
\hline Disease duration & 0.037 & 0.709 & 0.023 & 0.818 & -0.005 & 0.959 & -0.008 & 0.937 \\
\hline
\end{tabular}

Values are shown as $r$ ( $p$-value). $r$ is determined by Spearman's rank correlation test; BASDAI- The Bath Ankylosing Spondylitis Disease Activity Index, BASFIThe Bath Ankylosing Spondylitis Functional Index, BAS-G - The Bath Ankylosing Spondylitis Patient Global score, CRP - C-reactive protein, ESR - erythrocyte sedimentation rate, TNF - tumour necrosis factor; IL - interleukin; ${ }^{*} p<0.05,{ }^{* *} p<0.0001$

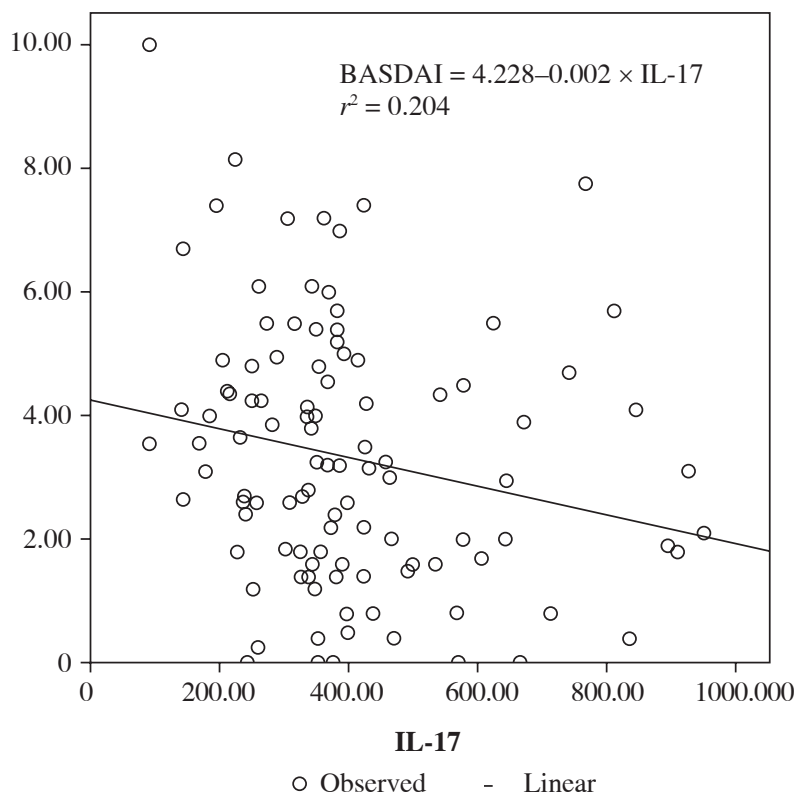

Fig. 1. Negative correlation between serum IL-17 levels and BASDAI values in AS patients

was a very strong positive correlation between IL-17 and IL-23 $(r=0.933 ; p<0.0001)$. No significant correlation was found between TNF- $\alpha$ and IL- 6 levels and between these parameters and IL-17 and IL-23 values (Table 2, Fig. 1).
According to extra-articular joint involvement, no significant differences were found between the values of TNF- $\alpha$ and IL- 6 of the extra articular-AS group and the values of non-extra-articular-AS group. However, IL-17 and IL-23 levels of extra-articular AS patients were found to be significantly lower than those of the non-extra-articular-AS group $(p<0.05)$ (Table 3$)$.

\section{The SNPs of IL-23R analysis}

The genotype frequencies of the two SNPs in AS patients and healthy controls are shown in Table 4. The genotype of Arg $381 \mathrm{Gln}$ genotype was present in $3.7 \%$ of AS patients and $2.5 \%$ of healthy controls $(p=0.633$, odds ratio $[\mathrm{OR}]=1.724)$. The overall genotype distribution of rs11209026 SNP appeared different between AS patients and healthy controls; however, it did not reach statistical significance $(p>0.05)$.

The genotype of Val362Ile genotype was present in $8.3 \%$ of AS patients and $0.0 \%$ of healthy controls $(p=0.069$, odds ratio $[\mathrm{OR}]=0.074)$. The overall genotype distribution of rs41313262 SNP appeared different between AS and healthy controls; however, it did not reach statistical significance $(p>0.05)$ (Table 4).

In the group as a whole, there was no significant difference in serum concentrations of any of the cytokines and the clinic parameters (BASDAI, BASFI, BASMI) between the patients with IL-23R rs4131362 heterozygous geno-

Table 3. Comparison of study parameters in patients with and without extra articular involvement

\begin{tabular}{lcccc}
\hline Parameter & $\begin{array}{c}\text { Extra articular-AS } \\
(\boldsymbol{n}=\mathbf{2 9})\end{array}$ & $\begin{array}{c}\text { Non-extra articular-AS } \\
(\boldsymbol{n}=\mathbf{8 0})\end{array}$ & $\begin{array}{c}\text { Healthy control } \\
(\boldsymbol{n}=\mathbf{4 0})\end{array}$ & $\boldsymbol{p}$-value \\
\hline $\mathrm{TNF}-\alpha, \mathrm{pg} / \mathrm{ml}$ & $10.9 \pm 2.9$ & $9.8 \pm 3.0$ & $10.4 \pm 2.0$ & 0.161 \\
\hline $\mathrm{IL}-6, \mathrm{pg} / \mathrm{ml}$ & $60.6 \pm 35.6^{1}$ & $54.3 \pm 27.3^{1}$ & $37.9 \pm 14.0$ & 0.001 \\
\hline $\mathrm{IL}-17, \mathrm{ng} / 1$ & $331.8 \pm 174.1^{2,3}$ & $427.7 \pm 188.9^{2}$ & $574.0 \pm 197.8$ & $<0.0001$ \\
\hline $\mathrm{IL}-23, \mathrm{ng} / \mathrm{l}$ & $267.9 \pm 179.5^{2,3}$ & $396.4 \pm 251.8^{1}$ & $502.0 \pm 228.4$ & $<0.0001$ \\
\hline
\end{tabular}

${ }^{1}$ significantly different from healthy control at $p<0.05,{ }^{2}$ significantly different from healthy control at $p<0.001,{ }^{3}$ significantly different from non-extra-articularAS at $p<0.05$ 
type (Val362Ile) and those with the wild-type genotype (Val362Val).

\section{Discussion}

Interleukin 23 is not only synergistic with IL-6 and IL-1 to stimulate Th17 development, but also it stimulates Th17 development and prolongs IL-17 production [12]. In the present study, a strong positive correlation between serum IL-23 and IL-17 levels in AS patients and in the control group confirms this association between these two cytokines.

Although the aetiopathogenesis of AS is not fully understood, some studies have suggested that the increase in blood levels of certain pro-inflammatory cytokines such as IL-1 $\beta$, IFN- $\gamma$, TNF- $\alpha$, IL-6, IL-17, and IL-23 may play a role in the pathogenesis $[5,15,22,23]$. These theses are supported by evidence that the symptoms and activity of the disease can be relieved by blocking these cytokines. Shen et al. found that serum IL-17 levels in RA, an inflammatory disease, were strongly associated with disease activity and CRP concentration [23]. In a study by Chen et al. it was found that serum concentrations of IL-23 and IL-17 were elevated in AS patients [24]. Also, Benham et al. showed a relationship between IL-23 and SpA progression in experimental animal model studies [25]. This association has been confirmed by reported clinical trials of elevated serum and synovial fluid IL-23 levels in AS patients. In these studies, the role of these cytokines in the pathogenesis of the disease has been explained by the high IL-23 production by macrophages in AS patients in response to lipopolysaccharide and by the demonstration of IL-17-positive cells in AS facet joints [26, 27]. In addition to this, high IL-17 levels in synovial fluid of patients with reactive arthritis and unspecified $\mathrm{SpA}$, excessive secretion of TNF-alpha and IL-6 in sacroiliac joints of AS patients, and increased frequency of IL-23-positive cells in facet joints were findings that supported this hypothesis in previous studies. These studies have also reported that this inflammatory process is also characterized by increased circulating levels of inflammatory cytokines such as TNF- $\alpha$, IL-6, IL-17, IL-23, and IL-33. However, previous studies which were about systemic inflammation in AS have not been fully described because of the number of similar samples and the absence of selected patient groups [27, 28]. Regarding the pathway of IL-17/IL-23 in AS patients, there are also studies that found different results. In a study by Sveaas et al., it was reported that there was no significant difference in serum IL-17 levels between AS patients and controls [29]. Ciccia et al. found an association between IL-17 overexpression and increased IL-17 expression in Chron patients. They did not find such an increase in IL-17 levels in AS patients, and they held IL-23/IL-23R dysregulation responsible for the development of these lesions [30]. Kayıkçı et al. in their study about psoriatic arthri-
Table 4. Distribution of IL-23R genotypes in the AS $(n=109)$ patients and healthy control group $(n=40)$

\begin{tabular}{|c|c|c|c|}
\hline Genotype & $\begin{array}{c}\text { AS patients } \\
n(\%)\end{array}$ & $\begin{array}{c}\text { Health control } \\
n(\%)\end{array}$ & $p$-value \\
\hline IL-23R rs11209026 & & & 0.633 \\
\hline 381Arg/Arg & $105(96.3)$ & 39 (97.5) & \\
\hline $381 \mathrm{Arg} / \mathrm{Gln}$ & $4(3.7)$ & $1(2.5)$ & \\
\hline $381 \mathrm{Gln} / \mathrm{Gln}$ & $0(0)$ & $0(0)$ & \\
\hline IL-23R rs4131362 & & & 0.069 \\
\hline $362 \mathrm{Val} / \mathrm{Val}$ & $100(91.7)$ & $40(100)$ & \\
\hline $362 \mathrm{Val} / \mathrm{Ile}$ & $9(8.3)$ & $0(0)$ & \\
\hline 362 Ile/Ile & $0(0)$ & $0(0)$ & \\
\hline
\end{tabular}

tis, which is known to resemble spondyloarthropathies in terms of immune response, reported that serum IL-17 and IL-23 levels were lower in PsA patients than in psoriasis patients and control groups. In our study, consistent with earlier studies, we found higher IL-6 levels in patients with AS than the control group but no significant differences between the levels of TNF- $\alpha$ [31]. In our study, serum levels of IL-17 and IL-23 were lower in both active and inactive AS patients when compared to the control group. This was similar to the results of the study by Kayıçı et al. on PsA patients. Unlike other various studies, the low serum IL-17 and IL-23 levels of AS patients was an interesting finding for us.

The results of our study have prompted us to question whether the low levels of IL-17 and IL-23 that we found in AS patients are associated with disease activity. For this purpose, active AS patients were compared with inactive AS patients and a control group. However, no significant difference was found between serum levels of IL-17 and IL-23 in patients with active AS and inactive AS. In the literature, the relationship between AS disease activity, function, and spinal mobility and levels of IL-17 and IL-23 have not been fully elucidated [24]. However, it has been shown to have a marked decline in inflammation and disease activity following TNF, IL-17, and IL-12/23 blockade of inflammatory pathways in the SpA. In a study of the relationship between IL-17 and IL-23 levels and disease activity in RA and AS patients by Melis et al., it was reported that plasma levels of these cytokines have been strongly associated with disease activity in RA patients, but not in AS patients [32]. A study by Taylan et al. reported that there was no difference between serum IL-6, IL-12, IL-17 and IL-23 concentrations of active and inactive AS patients and no association between BASDAI, BASFI and CRP, IL-17 and IL-23 levels. However, in that study, it was reported that BASMI, which is a compound index of spinal cord activity and reflects the severity of the disease, has a weak positive relationship with IL-23 
but no association with IL-17 [33]. In our study there was a weak positive correlation between IL-17 and IL-23 levels and ESR values in AS patients, and a weak negative correlation between IL-17 and BASDAI values. However, no significant difference was found between serum levels of IL-6, TNF- $\alpha$, IL-17, and IL-23 in patients with active AS and inactive AS. These results were similar to those from studies showing no association between disease activity in AS and serum levels of IL-17 and IL-23 [3, 5, 7, 33]. However, the weak negative correlation between IL-17 and BASDAI values, in particular, suggests that the reduction in this cytokine level should be assessed in the pathogenesis of AS. In our study, the IL-17/IL-23 pathway was also evaluated in AS patients with extra-articular involvement, which was not previously investigated in the literature. Our findings showed that serum IL-17 and IL-23 levels in AS patients with extra-articular involvement are lower than those of patients without extra-articular involvement. Dysregulation of the IL-23/IL-17 pathway, which is caused by decreased IL-17 and IL-23 levels in systemic circulation, may lead to systemic chronic autoimmune inflammation causing extra-articular involvement.

IL-23R is a key factor in the regulation of TH17 cells, which is a newly defined effector T cell subset [34]. It was revealed that the IL23R variant rs11209026 (Arg381Gln) caused a selective deterioration of IL-17 production by reduced STAT3 phosphorylation, which provides protection against AS [34-36]. The identification of IL-23 receptor polymorphisms in association with AS, psoriasis and Crohn's disease suggests a potential role for IL-23 in the pathogenesis of these diseases. The main source of IL-23 expression in subchondral bone marrow and spinal subchondral fibrous tissue in AS patients has also been found in MPO + cells and macrophages [27]. Di Meglio et al. and Sarin et al. showed a defective IL-23 signal in cells from individuals carrying the protective allele $[35,36]$. However, no significant effect on Th17 cell differentiation was observed because the frequency of Th17 cells in circulation was similar to the IL23R protector (A) and common (G) allele carriers. It has also been shown that Th17 cells of donors with A alleles and the $\mathrm{G}$ allele produce similar amounts of Th17 cytokine.

Until now, no functional work of IL23R variants has been reported. Furthermore, in studies targeting IL-23, it has not yet been elucidated how IL23R variation affects disease susceptibility. In this study, we evaluated the association of IL23R variants rs11209026 (Arg381Gln) and rs4131362 (Val362Ile) with the disease in AS patients. It was found that the IL23R variant rs4131362 is more frequent than IL23R variant rs11209026. This was an interesting finding for us because previous studies focused on the IL23R variant rs11209026, and this variant had been found to be associated with the pathogenesis of the disease. The serum levels of TNF- $\alpha$, IL-6, IL-17, and IL-23 and the BASDAI, BASFI, and BASMI values in this variant (rs4131362) were not significantly different from the variant rs11209026. Because there is no difference between the cytokine levels and clinical parameters between the two allelic variants (apart from the IL- 6 difference between the minor variants), these variants are not providing a new perspective in the genomic approach in AS. Although genotypic variation is highly informative in its ability to directly relate to disease activity, the nature of the IL23R R381Q genetic association makes it extremely difficult. The mutant allele frequency of reported IL23R Arg381Glngene variant was very low ( $3 \%$ in patients), so in our sample, no patient was homozygous for the mutant allele and very few were heterozygous. Hence, we cannot make meaningful comparisons between genotypes at this time. In this regard, extensive studies involving a larger number of patients are required.

\section{Conclusions}

In conclusion, IL-17 and IL-23 levels in systemic circulation in AS patients were not associated with disease activity. However, dysregulation of the IL-23/IL-17 pathway, which is caused by reduced IL-17 and IL-23 levels in the systemic circulation in AS, may contribute to the pathogenesis of the disease by systemically producing chronic autoimmune inflammation. Furthermore, the IL23R variant rs4131362, which has not been examined to date and is more common than the IL23R variant rs11209026, may be associated with AS.

\section{The authors declare no conflict of interest.}

\section{References}

1. Braun J, Sieper J (2007): Ankylosing spondylitis. Lancet 369: 1379-1390.

2. Brown MA, Kennedy LG, MacGregor AJ, et al. (1997): Susceptibility to ankylosing spondylitis in twins: The role of genes, HLA, and the environment. Arthritis Rheum 40: 18231828.

3. JaRvinen P (1995): Occurrence of ankylosing spondylitis in a nationwide series of twins. Arthritis Rheum 38: 381-383.

4. Castro-Santos P, Gutiérrez MA, Díaz-Peńa R (2014): Genetics of ankylosing spondylitis. Rev Med Chil 142: 1165-1173.

5. Gratacós J, Collado A, Filella X, et al. (1994): Serum cytokines (IL-6, TNF-alpha, IL-1 beta and IFN-gamma) in ankylosing spondylitis: a close correlation between serum IL-6 and disease activity and severity. Br J Rheumatol 33: 927-931.

6. Miossec P, Korn T, Kuchroo VK (2009): Interleukin-17 and type 17 helper T cells. N Engl J Med 36: 888-898.

7. Chabaud M, Durand JM, Buchs N, et al. (1999): Human interleukin-17: a T cell-derived proinflammatory cytokine produced by the rheumatoid synovium. Arthritis Rheum 42: 963-970.

8. Kurasawa K, Hirose K, Sano H, et al. (2000): Increased interleukin-17 production in patients with systemic sclerosis. Arthritis Rheum 43: 2455-2463. 
9. Lowes MA, Kikuchi T, Fuentes-Duculan J, et al. (2008): Psoriasis vulgaris lesions contain discrete populations of Th1 and Th17 T cells. J Invest Dermatol 128: 1207-1211.

10. Wong CK, Ho CY, Li EK, Lam CW (2000): Elevation of proinflammatory cytokine (IL-18, IL-17, IL-12) and Th2 cytokine (IL-4) concentrations in patients with systemic lupus erythematosus. Lupus 9: 589-593.

11. Kastelein RA, Hunter CA, Cua DJ (2007): Discovery and biology of IL-23 and IL-27: related but functionally distinct regulators of inflammation. Annu Rev Immunol 25: 221-242.

12. Layh-Schmitt G, Colbert RA (2008): The interleukin-23/interleukin-17 axis in spondyloarthritis. Curr Opin Rheumatol 20: 392-397.

13. Wang X, Lin Z, Wei Q, et al. (2009): Expression of IL-23 and IL-17 and effect of IL-23 on IL-17 production in ankylosing spondylitis. Rheumatol Int 29: 1343-1347.

14. Wendling D, Cedoz JP, Racadot E (2009): Serum and synovial fluid levels of p40 IL12/23 in spondyloarthropathy patients. Clin Rheumatol 28: 187-190.

15. Wendling D, Cedoz JP, Racadot E, Dumoulin G (2007): Serum IL-17, BMP-7, and bone turnover markers in patients with ankylosing spondylitis. Jt Bone Spine 28: 187-190.

16. Ferguson LR, Han DY, Fraser AG, et al. (2010): IL23R and IL12B SNPs and haplotypes strongly associate with Crohn's disease risk in a New Zealand population. Gastroenterol Res Pract 2010: 539461.

17. van der Linden S, Valkenburg H, Cats A (1984): Evaluation of diagnostic criteria for ankylosing spondylitis. Arthritis Rheum 27: 361-368.

18. Akkoc Y, Karatepe AG, Akar S, et al. (2005): A Turkish version of the Bath Ankylosing Spondylitis Disease Activity Index: reliability and validity. Rheumatol Int 25: 280-284.

19. Yanik B, Gürsel YK, Kutlay S, et al. (2005): Adaptation of the Bath Ankylosing Spondylitis Functional Index to the Turkish population, its reliability, and validity: functional assessment in AS. Clin Rheumatol 24: 41-47.

20. Jenkinson TR, Mallorie PA, Whitelock HC, et al. (1994): Defining spinal mobility in ankylosing spondylitis (AS). The Bath AS metrology index. J Rheumatol 21: 1694-1698.

21. Braun J, Pham T, Sieper J, et al. (2003): International ASAS consensus statement for the use of anti-tumor necrosis factor agents in patients with ankylosing spondylitis. Ann Rheum Dis 62: 817-824.

22. Bal A, Unlu E, Bahar G, et al. (2007): Comparison of serum IL-1 beta, sIL-2R, IL-6, and TNF-alpha levels with disease activity parameters in ankylosing spondylitis. Clin Rheumatol 26: 211-215.

23. Shen H, Goodall JC, Hill Gaston JS (2009): Frequency and phenotype of peripheral blood Th17 cells in ankylosing spondylitis and rheumatoid arthritis. Arthritis Rheum 60: 16471656.

24. Chen WS, Chang YS, Lin KC, et al. (2012): Association of serum interleukin-17 and interleukin-23 levels with disease activity in Chinese patients with ankylosing spondylitis. J Chinese Med Assoc 75: 303-308.

25. Benham H, Rehaume LM, Hasnain SZ, et al. (2014): Interleukin-23 mediates the intestinal response to microbial $\beta$-1,3-glucan and the development of spondyloarthritis pathology in SKG mice. Arthritis Rheumatol 66: 1755-1767.

26. Romero-Sánchez C, Jaimes DA, Londońo J, et al. (2011): Association between Th-17 cytokine profile and clinical features in patients with spondyloarthritis. Clin Exp Rheumatol 29: 828-834.
27. Appel H, Maier R, Bleil J (2013): In situ analysis of interleukin-23- and interleukin-12-positive cells in the spine of patients with ankylosing spondylitis. Arthritis Rheum 65:15221529.

28. Braun J, Bollow M, Neure L, et al. (1995): Use of immunohistologic and in-situ hybridization techniques in the examination of sacroiliac joint biopsy specimens from patients with ankylosing-spondylitis. Arthritis Rheum 38: 499-505.

29. Sveaas SH, Berg IJ, Provan SA, et al. (2015): Circulating levels of inflammatory cytokines and cytokine receptors in patients with ankylosing spondylitis: a cross-sectional comparative study. Scand J Rheumatol 44: 118-124.

30. Ciccia F, Bombardieri M, Rizzo A, et al. (2010): Over-expression of paneth cell-derived anti-microbial peptides in the gut of patients with ankylosing spondylitis and subclinical intestinal inflammation. Rheumatology 49: 2076-2083.

31. Kayıkçı Ö, Pamuk Ö, Pamuk G, Arıcan Ö, et al. (2014): Helper 17 Cytokine Profile in Psoriatic Arthritis and Their Relations with Clinical Findings. New J Med 31: 163-167.

32. Melis L, Vandooren B, Kruithof E, et al. (2010): Systemic levels of IL-23 are strongly associated with disease activity in rheumatoid arthritis but not spondyloarthritis. Ann Rheum Dis 69: 618-623.

33. Taylan A, Sari I, Kozaci DL, et al. (2012): Evaluation of the T helper 17 axis in ankylosing spondylitis. Rheumatol Int 32: 82511-82515.

34. Burton PR, Clayton DG, Cardon LR, et al. (2007): Association scan of 14,500 nonsynonymous SNPs in four diseases identifies autoimmunity variants. Nat Genet 39: 1329-1337.

35. Di Meglio P, Di Cesare A, Laggner U, et al. (2011): The IL23R R381Q gene variant protects against immune-mediated diseases by impairing IL-23-induced Th17 effector response in humans. PLoS One 6:e17160.

36. Sarin R, Wu X, Abraham C (2011): Inflammatory disease protective R381Q IL23 receptor polymorphism results in decreased primary CD4+ and CD8+ human T-cell functional responses. Proc Natl Acad Sci U S A 108: 9560-9565. 